\title{
SÃO PAULO: \\ ALTERNATIVAS PARA UMA ECONOMIA EM CRISE NA DECCADA DE VINTE
}

\section{Luiza Helena Schmitz Kliemann}

A presente análise propōe-se a verificar as possibilidades econômicas existentes no Estado de São Paulo na década de vinte que teriam sido percebidas pelos órgãos governamentais como alternativas para a economia baseada no café, naquele momento, debatendo-se com séria crise.

Para tal tarefa faz-se necessário o uso de documentação oficial qual sejam Mensagens da Presidência do Estado e Relatórios da Secretaria de Agricultura, Comércio e Obras Públicas da época. Foram também utilizadas como apoio algumas pesquisas já concluidas pertinentes ao assunto e que estão citadas no corpo do trabalho.

A análise divide-se em três capitulos.

O primeiro pretende traçar um rápido perfil da crise da economia cafeeira mostrando sua irreversibilidade.

O segundo, baseado nos dados oficiais colhidos nos documentos citados pretende demonstrar as reais possibilidades de buscar na policultura, indústria e pecuária substituição para a monocultura e a agro-exportação cafeeira naquele momento.

O terceiro explora as atitudes governamentais com relação à produção econômica, procurando mostrar que os governos paulistas tinham consciência das possibilidades de diversificação econômica que o Estado oferecia e procuraram incentivá-la.

Para realização desta tarefa foi importante a contribuição dos colegas Nicolau Luppo e Palmira Teixeira que nos viabilizaram o contato com a documentação em São Paulo. 


\section{O CAFÉ: UM PERFIL DA CRISE DA DÉCADA DE VINTE}

$\mathrm{Na}$ inserção do Brasil no capitalismo internacional, o café representou o crédito necessário a todas as transaçōes econômicas efetuadas no estrangeiro e foi também responsável por uma configuração sócio-politica bastante peculiar durante a República Velha, representada pelo sistema oligárquico.

Se examinarmos a formação social brasileira, encontraremos, desde o século XIX, novos contingentes populacionais que, atraidos para as zonas cafeeiras, vieram engrossar as camadas rurais e urbanas, como colonos, pequenos proprietários ou trabalhadores urbanos, assalariados, e cujo resultado foi não só o crescimento populacional, mas o desenvolvimento econômico, o alargamento das fronteiras "civilizadas" do Brasil e o aumento dos problemas sociais.

Por outro lado, na medida em que o café passou a representar a riqueza nacional, o sistema político atrelou-se a ele pouco incentivando a diversificação econômica e muito auxiliando a cafeicultura em suas crises com: sistemas de valorização do produto, reformas financeiras (manutenção de cambio baixo, impostos visando retenção da expansão quando havia superprodução) ${ }^{1}$, criação de órgãos protetores do produto e, nos anos trinta, a queima dos cafezais.

Não cabe aqui uma análise detalhada de tal situação, mas nos parece que a manutenção do poder político nas mãos dos individuos originários das grandes regiōes produtoras, o sistema implantado pela "política do governadores", a direção dada à gerência dos negócios brasileiros deixam evidente posição privilegiada do café até meados da década de vinte e, a partir dai, com as sucessivas crises não mais contornáveis politicamente, a busca desesperada por parte dos órgãos governamentais e dos cafeicultores de salvar a produção e, concomitantemente, buscar alternativas para a economia.

Vamos centrar a presente análise na região de São Paulo, maior centro produtor de café do pais e região onde é mais palpável, pelo óbvio, o que referenciamos acima.

Segundo Mensagem do Presidente do Estado de São Paulo em 1926, a produção de café até aquela data foi a seguinte: 
TABELA 1

\begin{tabular}{c|c|c|c}
\hline ANOS & CAFEEIROS & $\begin{array}{c}\text { PRCIUÇAO } \\
\text { (ARROBAS) }\end{array}$ & $\begin{array}{c}\text { POR MII PES } \\
\text { (ARROBAS ) }\end{array}$ \\
\hline $1921-22$ & 871.897 .400 & 32.970 .800 & 37,6 \\
$1922-23$ & 299.239 .100 & 28.187 .900 & 31,3 \\
$1923-24$ & 949.149 .451 & 41.497 .420 & 43,7 \\
$1924-25$ & 951.288 .450 & 36.770 .400 & 38,6 \\
$1925-26$ & 966.142 .590 & 40.348 .700 & 41,7 \\
\hline
\end{tabular}

A previsão para o ano de $1926-27$ seria de uma colheita de 34.660 .000 arrobas o que se configuraria numa diminuição da produção, atribuída às pragas, e à decadência de "600 miIhões de cafeeiros com mais de vinte anos"3.

Fator mais importante no entanto, foi também a diminuição da exportação bem maior do que a da produção o que passou a implicar em alta estocagem do produto, conforme podemos observar abaixo

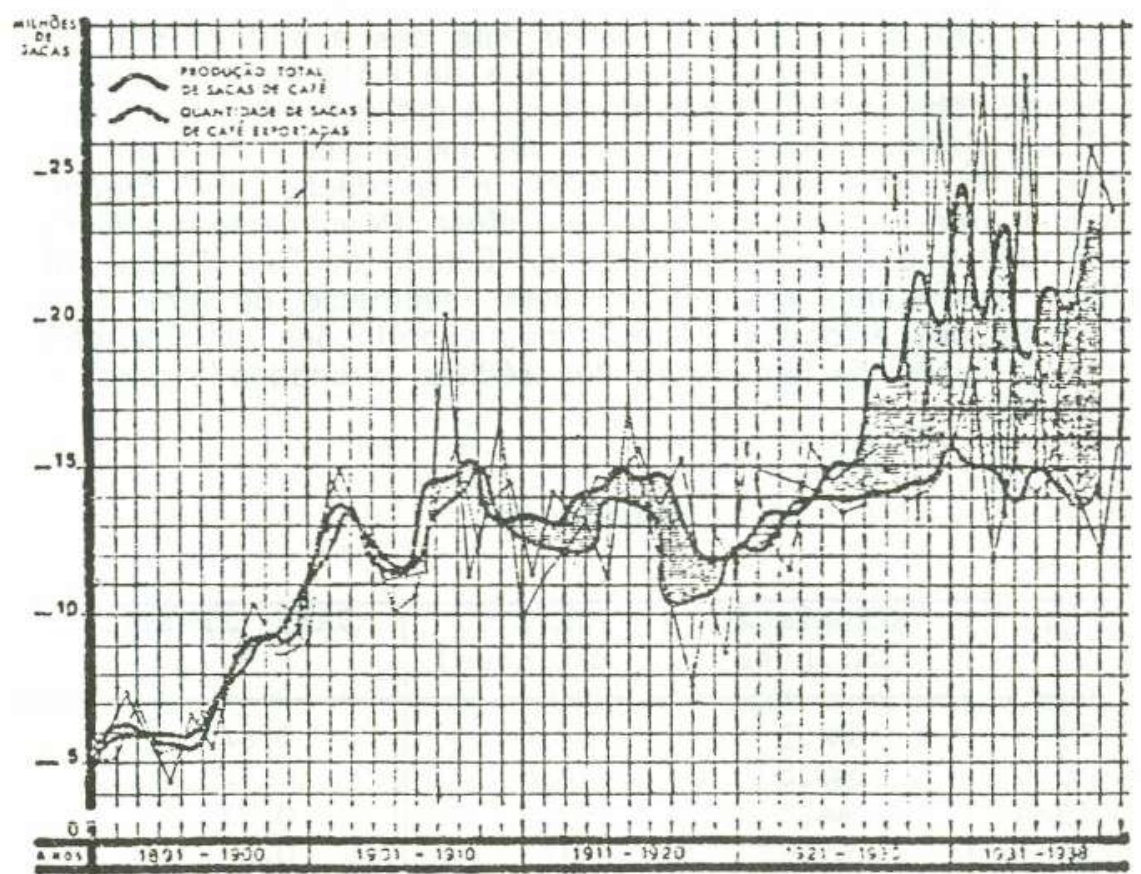

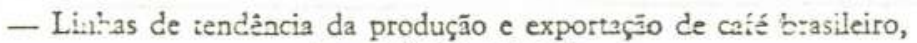
em períodos trienais 
Outro elemento que prejudicou foi o preço do café que, segundo Relatório da Secretaria da Agricultura de São Paulo, obteve em 1925 o preço por saca numa média de $228 \S 014$ e em 1926 somente $179 \S 5685$.

Ao chegar o ano de 1926 o governo paulista teve que contrair um empréstimo de 510 milhões para financiar o café armazenado, além das dividas contraídas por outros municipios de São Paulo para o mesmo fim6.

A crise internacional de 1929 atingiu o Brasil justamente no setor de exportação e num momento de grande safra que foi a de 1928 (ver Tabela 2). O sistema de defesa do café deter orou-se, o Estado foi impedido de saldar suas dividas, geram-se atritos entre governo e cafeicultores que, segundo Boris Fausto, desejavam emissões e pediam moratória para resolver a crise?.

A real'dade é que em São Paulo, em 1929, havia 29 miIhões de sacas de café estocadas para uma exportação de 14,3 milhões 8 .

O fato de existir um crescimento das exportações e da produção em alguns anos da década de vinte (como se pode ver nas tabelas 1 e 2) não diminuiu a extensão da crise, pois tal fato devia-se primordialmente aos mecanismos de valorização como a que foi feita em 1921 e a criação de órgãos reguladores como o Instituto de Defesa Permanente do Café em 1922 e o Instituto de Café do Estado de São Paulo em 1924, este último, responsável pela construção de armazéns, controle dos estoques, controle das exportações, manutenção e distribuição de facilidades de créditos, propaganda para o consumo.

TABELA 2

\begin{tabular}{c|c|c|c}
\hline ANO & $\begin{array}{c}\text { EXPORTAÇO } \\
\text { (Emilhões) }\end{array}$ & $\begin{array}{c}\text { CAFE } \\
\text { (£milhões) }\end{array}$ & $\begin{array}{c}\text { CAFE EXPORTADO } \\
\%\end{array}$ \\
\hline 1920 & 82,3 & 52,8 & 0,64 \\
1925 & 102,8 & 74,0 & 0,72 \\
1929 & 94,8 & 67,3 & 0,71 \\
1930 & 65,7 & 41,2 & 0,63 \\
\hline
\end{tabular}


A crise no entanto, apesar de atenuada por este mecanismo, não foi sanada, o que levou, já a partir de 1924, a uma busca de alternativas econômicas, com reformas administrativas e incentivo a produção em geral, não só ao café, conforme passaremos a verificar.

\section{A POLICULTURA E A INDÚSTRIA, POSSIBILIDADES DE ALTERNATIVA}

No presente capitulo, pretendemos demonstrar o panorama econômico de São Paulo na década de vinte, buscando através da reunião de dados sobre os principais produtos, confirmar a hipótese inicialmente levantada.

Devido a economia cafeeira e a todas as transformações que a mesma trouxe consigo, conforme vimos anteriormente, São Paulo desenvolveu-se de maneira que

"o recenseamento de 1920 registrava na área do Estado, 4.145 fábricas, que ocupavam 83,998 operários com produção de valor aproximado de um milhão de contos de réis". 10

A partir de então o crescimento industrial acelerou-se e as indústrias téxte!s foram a base do mesmo, tendo à frente o algodão e a seda esta última incentivada em plena crise econômica dos anos vinte.

O relatório da Secretaria da Agricultura de São Paulo diz que, devido ao câmbio baixo que dificultava a importação de artigos estrangeiros, havia na época prosperidade industrial:

"Em 1923 só os tecidos de algodão, lã e seda figuravam com mais da metade do valor total. Alcançam quase o triplo do que se produziu em 1922."11

Já no ano de 1925, o otimismo não é tão grande:

"Devido a revolta de 1924, a indústria manufatureira sofreu sensivel enfraquecimento nos 2 anos mais recentes. A produção de 1925, ainda não apurada, ficou inferior a do ano precedente, devido a crise de energia elétrica que paralisou as fábricas alguns meses do ano. A produção 
de tecidos baixou em 1924, aumentaram a de calçados, bebidas e chapéus. Nossas indústrias lutam com dificuldades, a capacidade das fábricas foi muito elevada com as facilidades de créditos trazidos pela inflação monetária. Em conseqüência a produção cresceu desproporcionalmente com as necessidades do mercado interno."'12

Data desta época o início das restrições para importação de maquinaria têxtil, o que foi aplaudido pelos industriais paulistas que temiam novos aumentos no número de fábricas e a conseqüente superprodução.

"As importações de maquinaria de fiação e tecelagem nesses anos (1924-1925) cairam em $17 \%$ em relação ao nível de 1926 , enquanto as importações de teares cairam em $6 \%$ no mesmo período."13

O problema da indústria, parece, passava a ser muito mais um problema de mercado do que realmente de incentivo e desenvolvimento próprios, o que não excluia seu caráter subordinado com relação à economia cafeeira.

\section{Seda}

Favorecida pela baixa cambial dos primeiros anos da década de vinte, prosperou a indústria da seda, pois tornava-se mais difícil a importação de manufaturas estrangeiras. Por Lei de 30 de dezembro de 1924 foi criada a Sociedade Anônima "Indústria da Seda Nacional" com um capital de 1500 contos de réis sediada na cidade de Campinas. Esta sociedade subvencionada pelo governo tinha por obrigações, selecionar o bicho da seda, promover a profilaxia da produção e fornecer óvulos aos criadores além de mudas de amoreiras. 14

No ano de 1924 em função da convulsão interna do Estado de São Paulo ocasionada pelos movimentos revolucionários houve um decréscimo na produção, mas se observarmos o ano de 1927 e o compararmos com o de 1923 (conforme Tabela 3) veremos um substancial desenvolvimento: 
TABELA 3

\begin{tabular}{rrrrrrr}
\hline ANO & FABRICAS & TEARES & FUSOS & FORÇA & OPERARIOS & $\begin{array}{c}\text { PRODUÇAO } \\
\text { (Kg) }\end{array}$ \\
\hline 1923 & 12 & 639 & 470 & 759 & 2.115 & 65.890 \\
1927 & 40 & 1.579 & 6.878 & 2.443 & 5.195 & 97.212 \\
\hline
\end{tabular}

Os dados da tabela referem-se aos tecidos e fitas de seda. Quanto aos pares de meia o ano de 1923 produziu 1.930 .672 pares e o de 1927, 3.714.932.

A partir de 1927 iniciou-se a experimentação do fabrico de seda sintética e a previsão oficial da produçăo para os próximos anos era de $400.000 \mathrm{Kg} .16$

\section{Algodão}

Desde a primeira grande guerra o plantio do algodão nas terras abandonadas pelo café passou a ser uma constante, no território paulista.

O grande auge da produção e industrialização foi após 1930 mas, nos anos vinte, já encontramos uma produção significativa e uma indústria crescente que, apesar da crise politica e econômica interna e da forçada diminuição das colheitas pela superprodução norteamericana no ano de 1925 , ergueu-se er. 1926.

São Paulo possuia, nesta data, sete zonas algodoeiras com a produção que segue:

Algodão em caroço

Algodão em pluma

Sementes

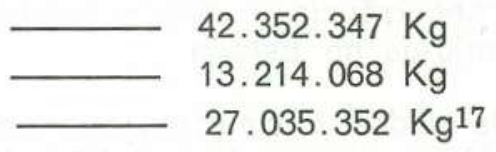

No que se refere à produção industrial, o quadro que conseguimos apurar através de dados oficiais, apesar de incompleto, foi o seguinte: 
TABELA 4

\begin{tabular}{l|c|c}
\hline \multicolumn{1}{c|}{ ANOS } & PRODUÇIO EM METROS & VAIOR \\
\hline 1922 & 217.263 .750 & $350.984 .644 \$ 000$ \\
1923 & 488.380 .092 & \\
1924 & 205.148 .127 & \\
1925 & 238.732 .628 & $417.585 .903 \$ 700$ \\
1926 & & \\
\hline
\end{tabular}

Podemos observar na Tabela 4 a instabilidade da produção industrial do algodão, cujo periodo de declinio corresponde justamente aos anos de superprodução agrícola e de convulsão política interna.

No ano de 1927, no entanto, a situação vai começar a es. tabilizar-se no setor industrial e São Paulo vai contar com 81 fábricas (sem incluir as malharias) com um total de 41.298 o. perários com 21.818 teares em funcionamento, utilizando uma força motriz de 43.019 cavalos. 19

Os incentivos e controle da produção agrícola começarão a aparecer a partir desta época, conforme veremos no capitulo seguinte.

\section{Carne Frigorificada}

Parece-nos importante arrolar, ao lado da indústria têxtil, a indústria de carne como uma das possibilidades alternativas para a economia paulista. Apesar da concorrência do Prata e do Rio Grande do Sul, a década de vinte viu prosperar em São Paulo alguns matadouros como Continental Armour e Anglo que, com maioria de capital estrangeíro, foram responsáveis pela concorrência a outros estabelecimentos congêneres, suplantando-os no Estado.

Os dados oficiais revelam um aumento nos abates e na produção e uma certa instabilidade na exportação devido a concorrência de mercado acima referida e a problemas cambiais. 
São Paulo: Alternativas...

\begin{tabular}{l|c|r|c|c|c}
\hline & PRODUCAO \\
\hline ANOS & BOVINOS & SUINOS & OVINOS & CAPRINOS & PRGDUÇAO (ton.) \\
\hline 1924 & 302.400 & 104.093 & 813 & - & - \\
1925 & 208.188 & 58.174 & 1.280 & 787 & 70.258 \\
1926 & 221.528 & 67.370 & 1.301 & 453 & 63.440 \\
1927 & 376.430 & 96.011 & 1.500 & 690 & 98.826 \\
\hline
\end{tabular}

\begin{tabular}{l|c}
\hline \multicolumn{2}{|c}{ EXPORTACXO } \\
\hline ANOS & TONETARAS \\
\hline 1924 & 42.117 \\
1925 & 26.301 \\
1926 & 5.526 \\
1927 & 26.129 \\
\hline
\end{tabular}

Esta instabilidade possuía, também, causas internacionais como revela Sandra Pesavento

"No plano internacional, os anos de 1924, 1925 e 1926 assinalaram um processo de intensa competição entre as companhias para conquistar a supremacia do mercado. A disputa acentuada favorecia os produtores de gado, porque a competição levava os frigorificos a elevarem os prejuízos, remunerando bem os fazendeiros. Manifestava-se aqui a intensa luta travada pelos dois blocos de frigoríficos mundiais: aqueles ligados ao grupo de Chicago e o concorrente londrino, não menos importante, dos Vestey Brothers. Quanto aos The Big Four de Chicago, haviam se transformado em três poderosos grupos, pois a Morr's fora absorvida pela Armour."22 
Fortalecida a Armour e rearticuladas as áreas de influência, a instabilidade diminuiu e houve aumento tanto da produção como da exportação.

\section{Açúcar e Outros Produtos}

Bastante revelador foi o aumento da produção açucareira que com 18 usinas, sem incluir os pequenos engenhos produziu:

\begin{tabular}{l|c}
\hline \multicolumn{2}{c}{ AÇỨCAR } \\
\hline ANOS & SACOS \\
\hline 1922 & 653.418 \\
1923 & 534.475 \\
1924 & 311.923 \\
1925 & 149.864 \\
1926 & 451.480 \\
1927 & 742.170 \\
\hline
\end{tabular}

A debacle do ano de 1924 foi atribuida pelos órgãos governamentais, a praga que assolou os canaviais e as secas prolongadas. A safra de 1927 foi prometedora e o açúcar, parece-nos, passou a ser também uma alternativa a ser incentivada.

Além dos que analisamos, outros produtos também foram responsáveis por equilibrar as finanças paulistas na década de vinte. As frutas, os cereais, os tubérculos e os oleaginosos começaram a competir no mercado interno com o Rio Grande do Sul, até então maior fornecedor de tais produtos.

A Mensagem do Presidente do Estado de São Paulo do ano de 1928 revela uma produção agrícola no valor de ...... 2.105.743.293\$330 do qual pertencia ao café 1.344.247.156\$500 - que revela já neste momento as possibilidades de diversificar a economia. 24 


\section{OS ÓRGÃOS GOVERNAMENTAIS E O QUADRO ECONÔMICO}

O exame da documentação oficial no que se refere a relatórios da Secretaria da Agricultura Comércio e Obras Píblicas do Estado de São Paulo, bem como das Mensagens do Presidente do Estado, deixam bem claras algumas medidas tomadas pelos sucessivos governos com o intuito de minorar a crise econômica proveniente da monocultura cafeeira.

Entre estas medidas estão os diversos serviços de Defesa Agrícola, a ampliação dos serviços portuários de Santos, a reorganização do Instituto Agronômico do Estado e a Criação do Instituto Biológico em 1927.

\section{Defesa Agrícola}

As constantes reclamações dos agricultores contra as pragas que destruiam as plantações fizeram com que o governo do Estado, interessado, pois, em expandir a produção, passasse a exercer rígido controle sobre a entrada de produtos, tubérculos e sementes no Estado de São Paulo. Para isto foram acionados: os Serviços de Distribuição de Sementes, a Comissão para debelação da Praga Cafeeira, e, pela queda na produção açucareira (conforme se vê na Tabela 5), a sugestão da criação de uma Estação Experimental da Cana.

\section{TABELA 5}

\begin{tabular}{l|l|l}
\hline ANos & SCs Açúcar & Iitros Alcool etc \\
\hline 1922 & 653.418 & 7.001 .141 \\
1923 & 534.475 & 7.017 .407 \\
1924 & 311.903 & 3.669 .088 \\
1925 & 149.864 & 2.546 .981 \\
\hline
\end{tabular}

Bem maior foi o incentivo dado pelo Serviço do Algodão que criou com a colaboração dos lavradores os campos de sementes. Segundo a Mensagem Presidencial de 1927

"O total da área aproveitada é de 173 alqueires. Se não houver contratempo de importância, a produção de sementes poderá atingir de 250 
mil a 300 mil kilos. Foram plantadas sementes das variedades selecionadas no Instituto Agronômico de Campinas, tais como Delfos, Salisbury, Express, Texas Big Ball Days long Staple e Campineiro num total de 4.203 quilos. 26

\section{Porto de Santos}

Em mensagem apresentada ao Congresso Legislativo no ano de 1925, o Dr. Carlos Campos, presidente do Estado da São Paulo narra as dificuldades de funcionamento do Porto de Santos provenientes do aumento da produção e congestionamento das vias de comunicação. Diz a mensagem:

"o problema do Porto de Santos reveste-se segundo judiciosos alvitres - de tríplice aspecto: - impõe-se o aumento do cais e dos armazéns, para a atracação dos navios, carga e descarga das mercadorias; o aumento de linhas e de material rodante da São Paulo Railway; e a redução das taxas que já oneram 0 comércio. 27

Nota-se na presidência do Estado uma preocupação com o futuro, e a mensagem deixa nítida a omissão do governo federal em tratar de assunto tão importante para São Paulo, quando afirma que desde 1912 o Estado requer melhorias no sistema de escoamento de sua produção e que as companhias concessionárias, tanto a Doca de Santos responsável pelos serviços portuários como a Railway, responsável pela ferrovia, não tinham interesse em tais reformas.

Retomando e ampliando a questão, o Secretário da Agricultura Comércio e Obras Públicas, no ano seguinte, apela à presidência para medidas com relação não só à reforma física da zona portuária, mas também à reforma tarifária.

"Enquanto subsistir o atual regime tarifário não será possivel cogitar-se neste Estado de desenvolver com a mesma intensidade a exportação de outro qualquer produto que não seja o café, dadas por um lado as condições decorrentes da situação privilegiada assegurada a São Paulo Railway Company em seus transportes obrigando a fretes elevados (...) Com o aumento da população, que hoje se eleva a cerca 
de seis milhões de habitantes, incrementando tantas outras fontes de produção estimulando a atividade mercantil, a renda da Cia. Doca de Santos elevou-se de $187.000 \$ 000$ em 1892 a $37.954 .000 \S 000$ em 1924"; 28 o que não justificava as tarifas elevadas.

Parece existir já neste momento a visão da necessidade de buscar alternativas para uma economia em crise, busca esta que, inclusive, ataca posições antes não contestadas como aquelas referentes ao domínio do capital estrangeiro nos setores de prestação de serviços. A leitura do relatório deixa também muito claro que os órgãos governamentais viam que apesar do café ser ainda o grande produto de exportação, estava em declínio e que a policultura precisava ser incentivada, conforme segue:

"Daí ver-se que a sujeitar-se o algodão, os ce-
reais, às mesmas tarifas constritoras do café
à razão de 5 réis o quilo, perdurarem os mes-
mos gravames que incidem sobre as carnes
congeladas, as madeiras, as frutas e outros gê-.
neros, a persistirem as tributações de trans-
portes, carregamento das mercadorias de ex-
portação, fora o mesmo que dificultar a saída
de outro qualquer serviço portuário." 29

O secretário encerra o relatório solicitando ao presidente que viabilize junto ao Ministério da Viação a redução de taxas sobre o algodão, carnes frigorificadas, frutas e cereais, numa nítida posição pró diversificação econômica cujo prenúncio se anunciava conforme vimos no capitulo anterior.

\section{Instituto Agronômico}

Pela Lei 2227A de 19/12/1927 foi reorganizado o já existente Instituto Agronômico do Estado de São Paulo. Segundo a Mensagem presidencial do ano de 192830 o abandono dos solos esgotados pelo café, a má distribuição das terras teriam demonstrado a necessidade de criar um órgão que efetivamente cuidasse destes assuntos. Assim sendo, o Instituto Agronômico teria como incumbência:

- estudo do solo

- distribuição dos tipos de terra de acordo com seu valor para cultura 
- classificação das plantas

- experimentação de culturas

- aconselhamento de agricultores no que se refere à prática agrícola e a economia rural

- divulgação de trabalhos sobre lavoura e pecuária.

Além destes afazeres, o Instituto junto com o governo do Estado estaria interessado em pesquisar adubos sintéticos e conseguir a fixação do azoto atmosférico bem como em experimentar a adubagem em determinadas regiões através do apatite.

\section{Instituto Biológico}

Também numa preocupação com a defesa da produção agrícola e pastoril foi criado em 1927 o Instituto Biológico que, segundo Mensagem do Presidente do Estado de São Paulo, então Dr. Julio Prestes, teria "a seu cargo o estudo teórico e prático das questões que interessam a defesa agricola e animal'31, o que poderiamos especificar como:

- fiscalização de inseticidas e congêneres

- combate às pragas

- desenvolvimento de pesquisas na área

- exames de mudas e sementes que entrassem pelo Porto de Santos

- criação de postos de prestação de serviços em todo o Estado.

Com a mesma preocupação existente para a criação dos órgãos que acima descrevemos, o governo do Estado fomentou a imigração, as pesquisas com relação ao petróleo, a Escola Agrícola, a criação do Museu Agrícola e Industrial conforme se vê na mensagem de 1928.

\section{CONCLUSÃO}

Dentre as dificuldades que nos deparamos para a realização desta tarefa e a conseqüente confirmação da hipótese que inicialmente levantamos está a da diversidade e incompatibilidade dos dados numéricos referentes a produção, importação $\epsilon$ exportação. Na sua maioria estes dados são relatados em cada documento de forma diferente; ou os valores não correspondem ou o sistema de medida muda de um documento para o outro o que faz necessária uma exaustiva transposição, por vezes inoperante. 
A par disto, no entanto, nos foi possível perceber que, na década de vinte, o Estado de São Paulo possuia condições de diversificar sua economia e que havia interesse ligado a esta diversificação. Constatamos também que os órgãos governamentais tinham consciência da realidade econômica e inclusive criaram uma série de órgãos auxiliares para incentivar a policultura e a defesa agrícola. Houve também preocupação de projetar para o futuro, como no caso do Porto de Santos e das pesquisas em torno dos adubos, sementes e seda sintética.

Não chegamos a analisar o comportamento das elites oligárquicas com relação a este assunto, mas parece-nos que aqui poderia estar o germe de determinadas dissidências se faz-se necessária uma pesquisa com relação ao assunto.

Como baseamos nosso trabalho nas fontes oficiais sem termos utilizado, para cotejar, com estas fontes, os jornais, atas de assembléia discursos parlamentares, acreditamos que os resultados aqui obtidos são parciais e que a pesquisa poderia ser ampliada e aprofundada com base neste material.

Pontificia Universidade Católica do Rio Grande do Sul Porto Alegre - Brasil

\section{NOTAS}

01 O Estado de São Paulo decretou em 1902 um imposto de $2.000 \$ 000$ sobre cada alqueire de cultura de café novo. Esse dispositivo legal devia vigorar por um quinqüênio, mas foi prorrogado ao cabo do seu termo por mais cinco anos. Era de fato a proibição de novas plantaçōes. Simonsen, Roberto C. Evolução Industrial do Brasil e outros estudos. São Paulo, Ed. Nacional e USP, 1973 (Brasiliana vol. 349) p. 220.

02 Mensagem apresentada ao Congresso Legislativo em 14 de julho de 1927, pelo Dr. Antonio Dino da Costa Bueno Presidente do Estado de São Paulo p. 84.

03 Idem, p. 84.

04 Simonsem op. cit. p. 403.

05 Relatório apresentado ao Dr. Carlos Campos Presidente do Estado pelo Dr. Gabriel Ribeiro dos Santos, secretário da Agricultura Comércio e Obras Públicas. 1926.

06 Love, Joseph. Autonomia e Interdependência: Săo Paulo e a Federação Brasileira, 1889-1937 in História Geral da Civilização Brasileria. Tomo III. Estrutura de Poder e Economia (1889-1930). DIFEL. São Paulo, 1975 p. 62.

07 Fausto, Boris. Expansão do café e política cafeeira. in História Geral da Civilização Brasileira, op. cit. p. 247.

08 Buescu, Mircea. Evolução Econômica do Brasil, 4 ed. Riı de Janeiró, APEC, 1977 p. 153. 
09 Buescu op. cit. p. 154.

10 Canabrava, Alice. Esboço da História Econômica de São Paulo. in São Paulo, Terra e Povo. Globo-USP, P. Alegre, 1967, p. 38.

11 Relatório apresentado ao Dr. Carlos Campos, presidente do Estado de São Paulo, pelo Secretário da Agricultura Comércio e Obras Públicas Dr. Gabriel Ribeiro Santos. 1924.

12 Relatório apresentado ao Dr. Carlos Campos, presidente do Estado de São Paulo, pelo Secretário da Agricultura Comércio e Obras Públicas Dr. Gabriel Ribeiro Santos, 1925.

13 Stein, Stanley "A indústria de tecidos de algodāo durante a crise da década de trinta", in A Moderna História Econômica. Pelaez e Buescu, Rio de Janeiro, APEC, 1976.

14 Mensagem apresentada ao Congresso Legislativo em 14 de julho de 1925, pelo Dr. Carlos Campos presidente do Estado de São Paulo p. 116 .

15 Tabela elaborada a partir dos dados fornecidos pela Mensagem ditada do ano de 1925 e pela Mensagem ao Congresso Legislativo de 14 de julho de 1928 apresentada pelo Dr. Julio Prestes de Albuquerque, presidente do Estado de São Paulo.

16 Mensagem. 1928, p. 72.

17 Mensagem apresentada ao Congresso Legislativo em 14 de julho de 1927 pelo Dr. Antonio Dino da Costa Bueno, presidente do' Estado de São Paulo, p. 92.

18 Tabela elaborada a partir dos dados constantes nos relatórios e mensagens citadas, anos de 1925, 1926, 1927, 1928.

19 Mensagem citada, ano 1928, p. 70.

20 Tabela elaborada a partir dos dados constantes nas Mensagens e Relatórios citados anos de 1925, 1926, 1927, 1928.

21 Idem.

22 Pesavento, Sandra Jatahay. República Velha Gaúcha, Charqueadas, Frigorificos e Criadores. Porto Alegre, Movimento - IEL, 1980, p. 230.

23 Tabela elaborada a partir dos dados constantes nas Mensagens presidenciais dos anos de 1927 e 1928.

24 Mensagem citada, ano 1928, p. 75.

25 Mensagem citada, ano de 1927, p. 90.

26 Idem, p. 92.

27 Mensagem citada, ano 1925, p. 110.

28 Relatório citado, ano 1927, p. XXV.

29 Idem, XXV e XXVI.

30 Mensagem citada, ano 1928, p. 78.

31 Idem, p. 80.

32 Idem, p. 34 e 68. 